\title{
Intellectual Disability and Brain Creatine Deficit: Phenotyping of the Genetic Mouse Model for GAMT Deficiency
}

\author{
Luigia Rossi ${ }^{1,2,+}$, Francesca Nardecchia ${ }^{3,+}{ }^{\circ}$, Francesca Pierigè ${ }^{1}$, Rossella Ventura ${ }^{4,5}$, Claudia Carducci ${ }^{6}$, \\ Vincenzo Leuzzi ${ }^{3}\left(\mathbb{D}\right.$, Mauro Magnani ${ }^{1,2}{ }^{-1}$, Simona Cabib ${ }^{4,5}$ (i) and Tiziana Pascucci ${ }^{4,5, *(1)}$ \\ 1 Department of Biomolecular Sciences, University of Urbino "Carlo Bo", 61029 Urbino, Italy; \\ luigia.rossi@uniurb.it (L.R.); francesca.pierige@uniurb.it (F.P.); mauro.magnani@uniurb.it (M.M.) \\ 2 EryDel SpA, Via Sasso 36, 61029 Urbino, Italy \\ 3 Division of Child Neurology and Psychiatry, Department of Human Neuroscience, Sapienza University, \\ 00185 Rome, Italy; francesca.nardecchia@uniroma1.it (F.N.); vincenzo.leuzzi@uniroma1.it (V.L.) \\ 4 Department of Psychology and "Daniel Bovet" Center, Sapienza University, 00184 Rome, Italy; \\ rossella.ventura@uniroma1.it (R.V.); simona.cabib@uniroma1.it (S.C.) \\ 5 IRCCS Fondazione Santa Lucia, 00142 Rome, Italy \\ 6 Department of Experimental Medicine, Sapienza University, 00161 Rome, Italy; claudia.carducci@uniroma1.it \\ * Correspondence: tiziana.pascucci@uniroma1.it; Tel.: +39-06-4991-7514 \\ + These authors are equally contributed.
}

check for

updates

Citation: Rossi, L.; Nardecchia, F.; Pierigè, F.; Ventura, R.; Carducci, C.; Leuzzi, V.; Magnani, M.; Cabib, S.; Pascucci, T. Intellectual Disability and Brain Creatine Deficit: Phenotyping of the Genetic Mouse Model for GAMT Deficiency. Genes 2021, 12, 1201. https://doi.org/10.3390/ genes12081201

Academic Editor: Orazio Palumbo

Received: 29 June 2021

Accepted: 25 July 2021

Published: 2 August 2021

Publisher's Note: MDPI stays neutral with regard to jurisdictional claims in published maps and institutional affiliations.

Copyright: (c) 2021 by the authors. Licensee MDPI, Basel, Switzerland. This article is an open access article distributed under the terms and conditions of the Creative Commons Attribution (CC BY) license (https:// creativecommons.org/licenses/by/ $4.0 /)$.

\begin{abstract}
Guanidinoacetate methyltransferase deficiency (GAMT-D) is one of three cerebral creatine (Cr) deficiency syndromes due to pathogenic variants in the GAMT gene (19p13.3). GAMT-D is characterized by the accumulation of guanidinoacetic acid (GAA) and the depletion of $\mathrm{Cr}$, which result in severe global developmental delay (and intellectual disability), movement disorder, and epilepsy. The GAMT knockout (KO) mouse model presents biochemical alterations in bodily fluids, the brain, and muscles, including increased GAA and decreased $\mathrm{Cr}$ and creatinine (Crn) levels, which are similar to those observed in humans. At the behavioral level, only limited and mild alterations have been reported, with a large part of analyzed behaviors being unaffected in GAMT $\mathrm{KO}$ as compared with wild-type mice. At the cerebral level, decreased $\mathrm{Cr}$ and $\mathrm{Crn}$ and increased GAA and other guanidine compound levels have been observed. Nevertheless, the effects of $\mathrm{Cr}$ deficiency and GAA accumulation on many neurochemical, morphological, and molecular processes have not yet been explored. In this review, we summarize data regarding behavioral and cerebral GAMT KO phenotypes, and focus on uncharted behavioral alterations that are comparable with the clinical symptoms reported in GAMT-D patients, including intellectual disability, poor speech, and autistic-like behaviors, as well as unexplored Cr-induced cerebral alterations.
\end{abstract}

Keywords: GAMT deficiency; genetic mouse model; behavioral phenotyping; developmental delay

\section{Introduction}

In the brain, the creatine/phosphocreatine/creatine kinase system is essential in maintaining the high-energy phosphate levels necessary for central nervous system (CNS) development and functioning by regenerating, transporting, and buffering (adenosine triphosphate) ATP levels. Apart from this fundamental role in energy metabolism, creatine has been proposed as a neurotransmitter, since it is released from neurons in an action-potential-dependent manner, and acts as an agonist of postsynaptic $\gamma$ aminobutyric acid (GABA)-A receptors. Moreover, creatine has been reported to be one of the main cellular osmolytes in the CNS, and may be a potential regulator of appetite and weight in the hypothalamic nuclei. These and other functions of creatine in the CNS are well summarized and described [1]. As previously reported, the identification of creatine deficiency syndromes (CDS) caused by mutations in the L-arginine:glycine amidinotransferase (AGAT) [2], guanidinoacetate methyltransferase deficiency (GAMT) [3], and SLC6A8 
genes [4] highlights the essential role of intact creatine metabolism in psychomotor development and cognitive function in humans.

Animal models of AGAT, GAMT, and SLC6A8 deficiency have been successfully developed, and provide a unique opportunity to study specific aspects of these rare pathologies in depth and develop targeted therapeutic strategies. Since GAMT deficiency (GAMT-D) is considered to be the most severe CDS, we summarize data regarding biochemical and behavioral phenotypes of GAMT knockout (KO) mice in order to highlight similarities and possible differences between the mouse model and human pathology, and the behavioral alterations comparable with clinical symptoms reported in GAMT-D patients.

Though GAMT-D animals exhibit biochemical phenotyping (tissue and body fluid metabolite profiling) that parallels the biochemical phenotype of human patients, these animals develop only a mild cognitive deficit, in contrast to the severity seen in humans [5]. After an uneventful pregnancy and delivery, GAMT-D patients show normal early postnatal development followed by developmental arrest that progresses to severe intellectual disability without speech, intractable epileptic seizures, and movement disorder [6].

\section{GAMT-D Syndrome: Clinical and Biochemical Profiling}

Cerebral CDS (CCDS), inborn errors of creatine metabolism, include the two creatine biosynthesis disorders-AGAT deficiency, and GAMT-D—and the creatine transporter (CRTR) deficiency. The two creatine synthesis defects (AGAT and GAMT deficiencies) have an autosomal recessive inheritance pattern, while CRTR deficiency is inherited and X-linked [7-9].

GAMT-D (EC 2.1.1.2) was first described in 1994 in a 22-month-old boy with cerebral creatine deficiency, developmental delay, and progressive extrapyramidal symptoms $[3,10]$. Low urinary creatinine excretion, reflecting a low body creatine pool, and accumulation of guanidinoacetate- the substrate of the deficient enzyme activity-were characteristic biochemical findings [11]. Approximately 130 patients with GAMT-D have been reported in literature, either as individual case reports or as small case series with an incidence of 1:550,000-1:2,640,000 [12-15].

The biochemical signature of GAMT-D is the increase in guanidinoacetic acid (GAA) concentration associated with low levels of creatine in bodily fluids (urine, plasma, and cerebrospinal fluid (CSF)) and the absence of (or very low) a creatine peak on proton magnetic resonance spectroscopy (H1-MRS) [6,7]. Urine GAA levels are about 1-30-fold, plasma GAA levels are 2-20-fold (10-fold on average), and CSF GAA levels are 5-50-fold higher than the upper limit of the GAA reference range [16-18].

The diagnosis is confirmed after identification of biallelic pathogenic variants in GAMT. More than 70 pathogenic variants have been described in GAMT-D patients, and about half of them are missense variants. Deletions, splice errors, frame shift, nonsense, and truncating mutations have also been reported $[6,7,17,19]$. Interestingly, in Portuguese patients, a high prevalence of the c.59G $>C$ pathogenic variant suggests a founder effect in this region [20].

Intellectual disability—the clinical hallmark of GAMT deficiency-is present in all affected patients, and is moderate or severe in most patients (60-90\%) $[7,17,21]$. Less frequently, developmental arrest and regression is reported [12,17,22].

The second consistent manifestation of the disease is epilepsy, which may be drugresistant in a small proportion of patients $[6,17,19,23]$. Febrile seizures may occur in the early phase of the disease, especially between 3 and 6 months of life, with epilepsy onset rarely delayed. There is no specific seizure pattern in GAMT-D, and the same patient can have different types of seizures at different ages. In the first months of life, lifethreatening tonic seizures with apnea or myoclonic seizures have been reported, while in infancy and childhood myoclonic astatic seizures, generalized tonic-clonic seizures, partial seizures with secondary generalization, drop attacks, atypical absences, and staring episodes are more frequent. In GAMT-D, no typical electroencephalography (EEG) pattern has been defined. An early derangement of background organization, interictal multifocal 
spikes, and slow wave discharges have been described, as well as focal abnormalities with prominent frontal region involvement $[17,23]$.

The third most frequent manifestation of GAMT-D is movement disorder, occurring in about half of patients-usually the most severe patients [17,21]. Movement disorder commonly consists of an extrapyramidal syndrome, mainly a hyperkinetic movement disorder. Dystonia and ataxia are the most common types, followed by chorea, choreoathetosis, ballismus, tremor, and myoclonus. Rett-like stereotypic movements of the hands have also been reported $[24,25]$. Bradykinesia and spasticity have been further associated with the disease $[6,17,19,24,26]$. Fever-induced ataxia lasting for days and slowly remitting after the illness has been described in only one patient [6]. Movement disorder is usually an early feature of GAMT-D, usually emerging before 12 years of age [21], although a late onset has been reported in a few patients [27,28]. In most—but not all-patients with movement disorder, bilateral pallidal lesions on brain magnetic resonance imaging (MRI) have been observed (hypointensity in T1-weighted and hyperintensity in T2-weighted images) $[6,19,21,23]$. In some patients, white matter alterations in the brainstem and pontine region, enlarged ventricles, and cerebral atrophy, in addition to basal ganglia lesions, have been reported $[17,24,29]$.

In GAMT-D, a progressive course has been suggested, especially with regard to motor features. In some late-diagnosed patients, progressive dystonia and action tremor, spasticity, and dystonic-ballistic movements emerging during the second decade of life have been reported, raising the possibility of a neurodegenerative nature of the disease $[17,21]$. However, the natural history of the disease is not known, due to its rarity and the initiation of specific treatment that improves clinical features.

Language seems to be especially affected in GAMT-D. Most patients never develop speech, or may speak fewer than 10 single words $[13,21,27,30,31]$. Only one verbal patient has been reported in the literature-A 13-year-old girl who was able to speak in short sentences and use syntax, pronouns, negatives, and tenses [27].

Behavioral disorder is frequently associated with GAMT deficiency, mainly consisting of autistic features, hyperactivity, and aggressive and self-injurious behavior [19,21]. Many patients are described as lacking eye contact, having difficulties with social communication or socio-adaptive skills, not pointing fingers at objects, and rarely imitating actions $[14,15,22]$. Only three patients have been described as having a happy predisposition and frequent bursts of laughter [13].

A muscle phenotype of GAMT-D patients is not defined, but muscle mass and strength do not seem to be affected, other than hypotonia $[17,19,26]$. Asthenia was reported in one patient [32], while another patient was described as slim but strong [25]. The treatment of GAMT-D, aimed at restoring brain creatine ( $\mathrm{Cr}$ ) (by $\mathrm{Cr}$ supplementation) and at preventing GAA accumulation by substrate restriction (by ornithine and sodium benzoate supplementation and arginine restriction) [33], has been proven to be effective in presymptomatic patients [33-35], although some doubts have been raised over the usefulness of sodium benzoate supplementation and an arginine-restricted diet [35,36]. However, the late start of the treatment improves pharmacological control of seizures, but has limited effect in ameliorating the neurological deficits $[6,17,21]$.

\section{GAMT KO Mouse Model}

Since systematic patient studies on the pathophysiology of CDS cannot be conducted due to the low incidence of this pathology, genetically-engineered mice represent an excellent experimental tool to investigate this disorder.

The generation of a KO mouse model for GAMT-D was reported for the first time in 2000 [37], and validated to study creatine deficiency in 2003 [38]. In a very elegant study [39], the authors showed that human and mouse tissues have comparable GAMT mRNA and protein expression patterns, clearly supporting the usefulness of this mouse model to study GAMT-D. They generated and described in detail a GAMT KO mouse model via targeted disruption of the open reading frame of the murine GAMT gene in 
the first exon in embryonic stem cells, which resulted in the creation of a null allele, as verified at the genetic, RNA, and protein levels. In the same work, the authors reported that GAMT KO mice show biochemical features in the serum, urine, brain, skeletal muscle, and heart that mirror many of the biochemical hallmarks of human disease. Indeed, they observed a marked increase in GAA and reduced $\mathrm{Cr}$ and creatinine (Crn) levels in the serum, urine, and brains of GAMT-/- mice. Moreover, high levels of phosphorylated form of GAA (PGAA) and reduced amounts of $\mathrm{Cr}$ phosphate (PCR) in the heart, skeletal muscle, and brain were detected using ${ }^{31} \mathrm{P}$ MRS. Since 2004, the GAMT-D mouse model has been the object of further studies. This review will focus on the main biochemical features in different tissues, especially the brain.

\subsection{Biochemical Profiling}

\subsubsection{Bodily Fluids}

Guanidine compound concentrations have been evaluated in the plasma/serum and urine of GAMT KO mice and compared with wild-type (WT) and heterozygous (HZ) mice [5,39]. In body fluids, much higher GAA levels in GAMT mice compared to controls were found, while $\mathrm{Cr}$ and $\mathrm{Crn}$ values were higher in control mice compared to GAMT-D mice (Table 1). The range of $\mathrm{Cr}$ and Crn decrease and GAA increase in GAMT-D mice is comparable with human patients $[8,11,16]$. Table 1 also shows more recent data obtained by Iqbal [40]. To obtain a better comparison, urine $\mathrm{Cr}$, $\mathrm{Crn}$, and GAA content have been reverted to $\mathrm{nmol} / 24 \mathrm{~h}$ instead of $\mu \mathrm{mol} / \mathrm{L}$, by assuming female C57BL/6J urinary output of $9.9 \pm 3.5 \mathrm{~mL} / 100 \mathrm{~g}$ BW/day [41] and $20 \mathrm{~g}$ animal BW as reported by Iqbal in Figure 1, Supplementary Materials of Ref. [40]. In addition to Cr, Crn, and GAA, additional guanidine compounds and metabolites were evaluated, though no significant differences were found between the analyzed groups [5,40].

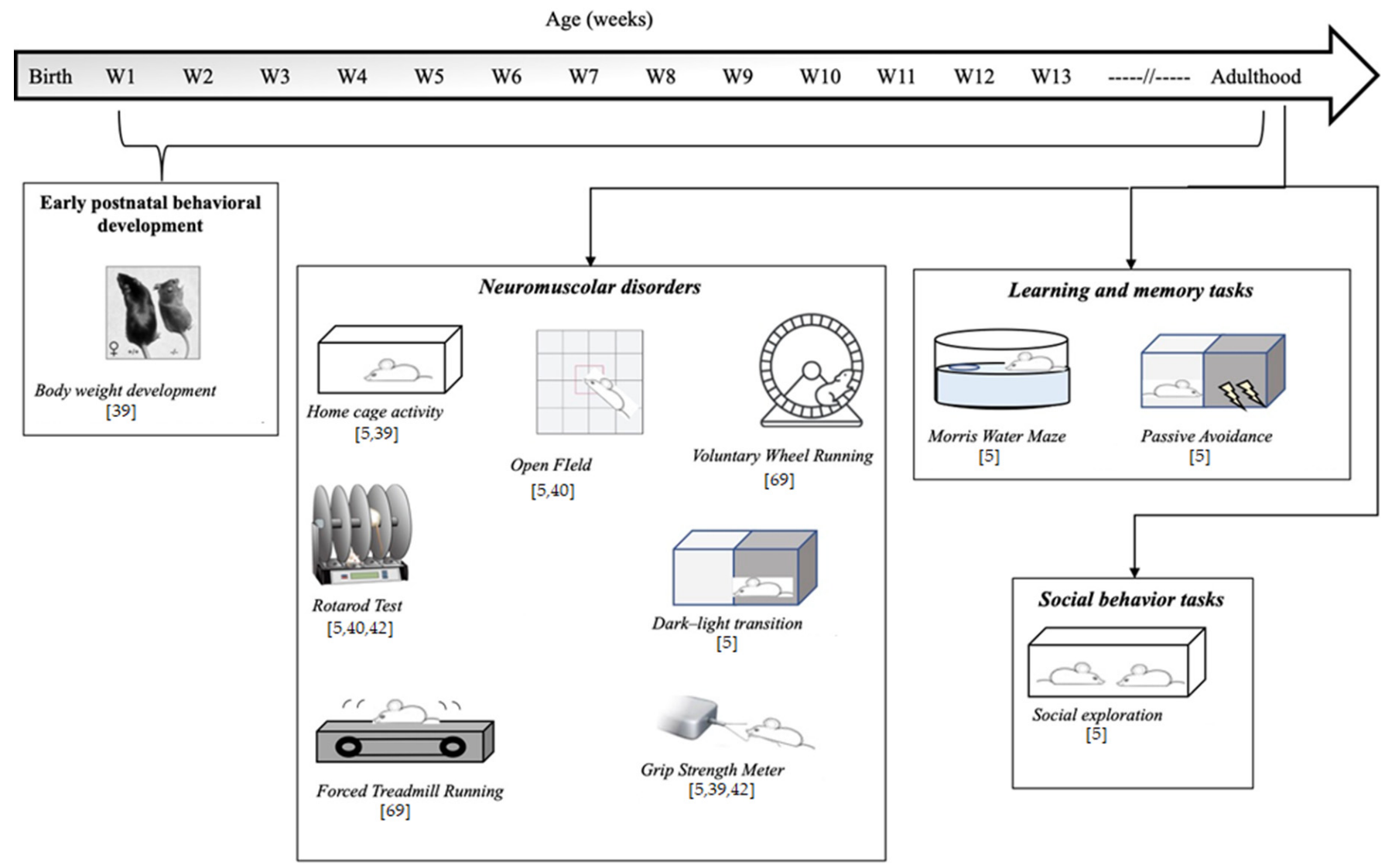

Figure 1. Schematic representation of behavioral tests reported in literature on GAMT knockout (KO), the genetic murine model of GAMT-D. 
Table 1. Cr, Crn, and GAA concentrations in the urine and plasma or serum of GAMT WT, HT, and KO mice.

\begin{tabular}{|c|c|c|c|c|c|c|c|c|c|}
\hline \multirow{2}{*}{ Tissue } & \multirow{2}{*}{ Compound } & \multicolumn{8}{|c|}{ Genotype } \\
\hline & & \multicolumn{3}{|c|}{ WT } & \multicolumn{2}{|c|}{$\mathrm{HZ}$} & \multicolumn{3}{|c|}{ KO } \\
\hline $\begin{array}{c}\text { Urine } \\
(\mathrm{nmol} / 24 \mathrm{~h})\end{array}$ & $\begin{array}{l}\text { Cr } \\
\text { Crn } \\
\text { GAA }\end{array}$ & $\begin{array}{c}13,490 \pm 3967 \\
9188 \pm 1753 \\
3005 \pm 880\end{array}$ & $\begin{array}{c}8394 \pm 2739 \\
6491 \pm 1336 \\
2023 \pm 575\end{array}$ & $\begin{array}{c}20,883 \pm 7603 \\
54.8 \pm 12 \\
320 \pm 37\end{array}$ & $\begin{array}{c}5130 \pm 1373 \\
6991 \pm 853 \\
2335 \pm 538\end{array}$ & $\begin{array}{c}5672 \pm 1203 \\
6206 \pm 926 \\
2065 \pm 522\end{array}$ & $\begin{aligned} 71 & \pm 56^{* *} \\
1153 & \pm 268^{* * *} \\
25,775 & \pm 2867^{* * *}\end{aligned}$ & $\begin{array}{c}47 \pm 36^{* * *} \\
536 \pm 124^{* * *} \\
19,015 \pm 2887^{* * *}\end{array}$ & $\begin{array}{l}4144 \pm 1496 \\
55.6 \pm 19.8 \\
372 \pm 27.4\end{array}$ \\
\hline $\begin{array}{c}\text { Plasma or } \\
\text { Serum } \\
(\mu \mathrm{mol} / \mathrm{L})\end{array}$ & $\begin{array}{l}\mathrm{Cr} \\
\text { Crn } \\
\text { GAA }\end{array}$ & $\begin{array}{c}172.4 \pm 16.4 \\
8.9 \pm 0.8 \\
1.9 \pm 0.5\end{array}$ & $\begin{array}{c}172 \pm 16 \\
8.89 \pm 0.73 \\
1.94 \pm 0.41\end{array}$ & $\begin{array}{c}1347 \pm 205 \\
5.5 \pm 0.8 \\
33.3 \pm 14.6\end{array}$ & $\begin{array}{l}187 \pm 32.7 \\
9.4 \pm 0.6 \\
2.4 \pm 0.3\end{array}$ & $\begin{array}{c}190 \pm 24 \\
9.50 \pm 0.94 \\
1.97 \pm 0.37\end{array}$ & $\begin{array}{c}12.9 \pm 8.1^{* * *} \\
1.3 \pm 0.3^{* * *} \\
117.4 \pm 32.1^{* *}\end{array}$ & $\begin{array}{l}11.56 \pm 7.1^{* * *} \\
<0.4-2.15^{\circ} \\
106 \pm 29^{*}\end{array}$ & $\begin{array}{l}822 \pm 416 \\
1 \pm 0.2 \\
97.6 \pm 7.8\end{array}$ \\
\hline \multicolumn{2}{|c|}{ Reference } & {$[39]^{A}$} & {$[5]^{B}$} & {$[40]^{C}$} & {$[39]^{A}$} & {$[5]^{\mathrm{B}}$} & {$[39]^{A}$} & {$[5]^{B}$} & {$[40]^{C}$} \\
\hline
\end{tabular}

${ }^{A}$ Values are expressed as mean \pm standard error of the mean (S.E.M). The mice analyzed included 6 WT, 8 HZ, and 10 KO. Statistical significance levels: ${ }^{* *} p<0.01,{ }^{* * *} p<0.001$ (two-tailed heteroscedastic $t$-test). ${ }^{B}$ Values are expressed as mean \pm S.E.M. The mice analyzed included $11 \mathrm{WT}, 9 \mathrm{HZ}$, and $16 \mathrm{KO}$ for urine and $5 \mathrm{WT}, 7 \mathrm{HZ}$, and $11 \mathrm{KO}$ for plasma. Asterisks indicate significant differences compared to the WT genotype (one-way ANOVA and Tukey's post hoc test: ${ }^{*} p<0.05$, $* * * p \leq 0.001{ }^{\circ}{ }^{\circ}$ indicates that a difference was observed but no statistical test could be performed because of values below the detection limit (DL)). ${ }^{C}$ Values are expressed as mean \pm S.E.M. There were 10 mice for each group (WT and $\mathrm{KO})$.

No significant differences in $\mathrm{Cr}$, Crn, or GAA concentrations were found between WT and HZ mice. Significant discrepancies may be observed in the values reported by Iqbal et al.-both in GAMT KO and WT mice-in comparison with those reported by Schmidt et al. and Torremans et al., except for plasma GAA and Crn values in KO mice. To date, it is not possible to justify this discrepancy and, therefore, further studies are necessary in order to evaluate the experimental conditions underlying these differences. In particular, it is necessary to evaluate: (1) breeding conditions; (2) diet; (3) when samples were taken; (4) analysis techniques; and (5) sex and age of the animals.

Moreover, in a recent study [42], GAA plasma levels of approximately $1000 \mu \mathrm{M}$ were detected in GAMT KO mice-a value at least 10 times higher than that reported by the authors cited in Table 1, further supporting the need to confirm data with different analysis methods.

\subsubsection{Skeletal Muscle}

Biochemical hallmarks of GAMT KO muscle tissue are generally characterized by a significant increase in GAA concentration and reduced $\mathrm{Cr}$ levels with respect to controls [5]. In addition, the presence of the PGAA and reduced PCR/ATP ratios have been observed [38,43].

MRS is a non-invasive bio-imaging tool used to investigate metabolites in vivo. MRS is largely exploited to analyze both muscle and brain metabolites in GAMT KO mice. In particular, the ${ }^{1} \mathrm{H}$ MR-sensitive nucleus has been used to evaluate PCR and choline compounds, such as $\mathrm{N}$-acetyl aspartate, taurine, lipids, etc. In contrast to human studies, PGAA is hard to detect in vivo with ${ }^{1} \mathrm{H} \mathrm{MR}$, since it becomes visible on murine muscle as a broad line only when $\mathrm{Cr}$ is almost completely depleted [38]. Instead, the ${ }^{31} \mathrm{P} \mathrm{MR}-$ sensitive nucleus has been used to detect PCR, PGAA, and ATP, mostly expressed as relative ratios. Before reviewing the results obtained by analyzing the MR spectra of muscle tissue as a whole, it should be emphasized that guanidine compounds were also evaluated in the muscle of GAMT WT, HZ, and KO mice on trichloroacetic acid (TCA)-extracted tissues analyzed using a suitable adapted amino acid analyzer [5]. Highly significant differences in GAA and $\mathrm{Cr}$ levels were observed between GAMT KO mice and controls. In particular, 14,450 $\pm 2088 \mathrm{nmol} \mathrm{GAA} / \mathrm{g}$ tissue was found in KO mice versus $1.88 \pm 0.43$ and $4.47 \pm 1.0 \mathrm{nmol} / \mathrm{g}$ in WT and HZ mice, respectively, reflecting GAA values thousands of times higher than control values. Cr was present in GAMT KO mice at levels about 10 times lower than those observed in WT and HZ mice $(1501 \pm 301 \mathrm{nmol} / \mathrm{g}$ tissue vs. $16,508 \pm 278$ and 18,788 \pm 2157 , respectively). In total, 13 guanidine compounds were evaluated by Torremans et al. [5], and other compounds-such as Crn, homoarginine, $\beta$-guanidinopropionic acid, and $\gamma$-guanidinobutyric acid-were significantly higher in the muscle of GAMT KO mice compared to controls. In Tables 2 and 3, results from in vivo ${ }^{1} \mathrm{H}$ and ${ }^{31} \mathrm{P}$ MRS analyses on the skeletal muscle of GAMT KO compared to WT mice 
are reported [38,43,44]. Table 2 also includes the aforementioned $\mathrm{Cr}$ and GAA values [5], reverted to $\mathrm{mM}$ by assuming a skeletal muscle tissue density of $1.06 \mathrm{~g} / \mathrm{cc}$ [45].

Table 2. Cr and GAA concentrations in the skeletal muscle of GAMT-D WT and KO mice.

\begin{tabular}{|c|c|c|c|c|c|c|c|}
\hline \multirow{2}{*}{ Tissue } & \multirow{2}{*}{ Compound } & \multicolumn{6}{|c|}{ Genotype } \\
\hline & & \multicolumn{3}{|c|}{ WT } & \multicolumn{3}{|c|}{ KO } \\
\hline Muscle (mM) & $\begin{array}{c}\mathrm{Cr} \\
\text { GAA }\end{array}$ & $\begin{array}{c}28.4 \pm 2.6 \\
-\end{array}$ & $\begin{array}{c}17.5 \pm 0.3 \\
0.002 \pm 0.0005\end{array}$ & $\begin{array}{c}27.7 \pm 3.9 \\
-\end{array}$ & $\begin{array}{c}8.9 \pm 3.8 \\
-\end{array}$ & $\begin{array}{l}1.6 \pm 0.3^{\text {*** }} \\
15.3 \pm 2.2^{\text {**** }}\end{array}$ & $\begin{array}{c}3.4 \pm 3.9 * \\
-\end{array}$ \\
\hline Refe & & {$[38]^{\mathrm{A}}$} & {$[5]^{B}$} & {$[44]^{\mathrm{C}}$} & {$[38]^{\mathrm{A}}$} & {$[5]^{B}$} & {$[44]^{C}$} \\
\hline
\end{tabular}

A There were $5 \mathrm{WT}$ and $7 \mathrm{KO}$ mice. ${ }^{\mathrm{B}}$ Values are expressed as mean \pm S.E.M. There were $4 \mathrm{WT}$ and $6 \mathrm{KO}$ mice. Asterisks indicate significant differences compared to the WT genotype (two-way ANOVA and Tukey's post hoc test: ${ }^{* * *} p \leq 0.001$ ). ${ }^{C}$ Values are expressed as mean \pm standard deviation. There were $4 \mathrm{WT}$ and $9 \mathrm{KO}$ mice. ${ }^{*}$ Significantly different from WT, with $p<0.05$. Cr and GAA are referred to as total pools.

Table 3. PCR and PGAA in the skeletal muscle of GAMT-D WT and KO mice.

\begin{tabular}{cccccc}
\hline \multirow{2}{*}{ Tissue } & \multirow{2}{*}{ Compound } & \multicolumn{3}{c}{ Genotype } \\
\cline { 3 - 6 } & & \multicolumn{3}{c}{ WT } & \multicolumn{3}{c}{ KO } \\
\hline \multirow{2}{*}{ Muscle (phosphate ratios) } & PCR/ATP & $2.66 \pm 0.11$ & $3.16 \pm 0.10$ & $0.76 \pm 0.33$ & N.D. \\
& PGAA/ATP & N.D. & N.D. & $1.78 \pm 0.42$ & $3.04 \pm 0.06$ \\
\hline \multirow{2}{*}{ Muscle (mM) } & PCR & $18.86 \pm 0.78$ & $22.40 \pm 0.71$ & $3.83 \pm 1.66$ & N.D. \\
& PGAA & N.D. & N.D. & $8.97 \pm 2.01$ & $15.32 \pm 0.30$ \\
\hline Reference & & {$[38]$} & {$[43]$} & {$[38]$} & [43] \\
\hline
\end{tabular}

All values are presented as mean \pm standard deviation. As suggested [46], PCR/NTP and PGAA/NTP ratios in Renema et al. are reported as PCR/ATP and PGAA/ATP ratios. N.D.: not detectable.

In addition, in Table 3, PCR and PGAA are expressed both as PCR/ATP and PGAA/ATP, and reverted to $\mathrm{mM}$, starting from ATP concentrations chemically determined by Kan et al. $(11.1 \pm 1.2 \mu \mathrm{mol} / \mathrm{g}$ dry weight and $15.6 \pm 1.1 \mu \mathrm{mol} / \mathrm{g}$ dry weight in GAMT KO and WT mice, respectively) [43], and by assuming the ratio of dry weight/wet weight to be 0.3:0.7 [46].

Residual Cr in GAMT KO muscle is likely caused by diet (creatine-free or not) or coprophagy if animals are not separated as soon as possible from dams and housed in individual cages, depending on the genotype $[39,43]$. However, $\mathrm{Cr}$ is always significantly lower than that observed in control mice, suggesting high-energy phosphate depletion in skeletal muscle. Of interest, the high PGAA/PCR ratio detected ( $3.4 \pm 3$ ) by Renema et al. [38] is probably due to: (1) active GAA uptake via the highly-expressed creatine transporter in muscle tissue, which is also able to transport GAA [47]; (2) endogenous GAA synthesis by AGAT [48]; and (3) the ability of creatine kinase (CK) to also use GAA as a substrate [49]. Despite the lower affinity of CK for PGAA, the latter compound functions surprisingly well in vivo as an energy buffer, as shown in a mild ischemic stress experiment [43]. In addition, PGAA accumulation in GAMT KO mice has recently been suggested as a probable explanation for less statin-induced muscle damage in GAMT-D mice compared to AGAT-deficient mice [50].

Moreover, marked in vitro [43] and in vivo [39] ATP changes were not present, leading to the hypothesis of adaptive changes in oxidative phosphorylation and in the mitochondria. In the mitochondria of GAMT KO compared to WT mice, Schmidt et al. [39] found a significant increase (of $67 \%$ ) in the absolute activity of ATP synthase-complex V of the respiratory chain and a marker of aerobic capacity (confirming previous observations by Ilas et al., 2000 [51] in human fibroblasts of GAMT-D patients) - higher (although not significantly) absolute activity of citrate synthase-a marker of mitochondrial content. However, despite the lack of PCR, the accumulation of PGAA, and some adaptive changes, no morphological alterations were observed via electron microscopy analysis of muscle tissue. More recently, metabolic marker enzymes have been investigated in the hind leg muscles of both AGAT and GAMT KO mice [52]. In particular, citrate synthase and cytochrome oxidase-complex IV of the respiratory chain—have been evaluated in the 
gastrocnemius (GAS), plantaris (PLA), and soleus (SOL) muscles, representing glycolytic, intermediate, and oxidative muscles, respectively. In GAMT KO mice, citrate synthase activity and cytochrome oxidase activity were higher in all three muscles compared to controls, confirming previous findings by Schmidt [39]. Moreover, both enzymes had significantly higher activity in males compared to females (citrate synthase in PLA and SOL, cytochrome oxidase in GAS and SOL), suggesting the importance of considering differences between muscles, as well as between males and females, when characterizing phenotypes. However, the changes in GAMT KO mice were modest compared to those in AGAT KO mice. The less severe phenotype of GAMT KO mice, as compared to human GAMT-D, could relate to the fact that they accumulate GAA, which functions as a substrate for cytosolic CK, albeit at a reaction rate 100 times slower [49]. According to the authors, $\mathrm{CK}$ involvement in the reaction with GAA may prevent activation of AMP-activated kinase (AMP-K) and, in turn, the stimulation of mitochondrial biogenesis, as in AGAT KO mice. In addition, since AMP-K is an inhibitor of anabolic pathway activity, its higher activity in this last animal model could also explain the observed muscle atrophy, which is only modest in GAMT KO mice.

Altogether, biochemical features of the skeletal muscle observed in GAMT KO mice-especially those observed with in vivo 31P MRS and 1H MRS - are similar to those observed in human GAMT-D [53].

\subsubsection{Brain}

The discovery of primary CDS caused by mutations in the genes encoding the $A G A T$ [2] and GAMT enzymes [3], or the creatine transporter SLC6A8 [4], has shed light on the role of creatine synthesis, metabolism, and transport in psychomotor development and cognitive function-in particular in the CNS, which appears to be the main tissue affected by these creatine deficiencies.

Concerning the GAMT KO brain, most of the authors who have already been cited for their studies carried out on the skeletal muscle of GAMT KO mice have also evaluated the metabolic features of the brain. Renema et al. [38] used 1H MRS to show that the $\mathrm{Cr}$ signal (Cr + PCR) was significantly reduced in the brains of GAMT KO mice. Interestingly, $\mathrm{Cr}$ reduction was more marked in the brain (83\%) than in the muscles $(69 \%)$, suggesting a slower uptake of orally-ingested $\mathrm{Cr}$ in the brain. Indeed, it was observed that only a small amount of $\mathrm{Cr}$ reaches the CNS through the blood-brain barrier (BBB) in rats [54], and thus the CNS must rely on endogenous synthesis of $\mathrm{Cr}$ for its needs. Similar values have been reported by other authors (Table 4). Recently, Sinha et al. [55] evaluated Cr and GAA content in the brains of GAMT KO mice, confirming the expected biochemical phenotype.

Table 4. Cr, Crn and GAA concentrations in the brain tissue of GAMT-D WT, HZ and KO mice.

\begin{tabular}{|c|c|c|c|c|c|c|c|c|c|}
\hline \multirow{3}{*}{$\begin{array}{l}\text { Tissue } \\
\begin{array}{l}\text { Brain } \\
(\mathrm{mM})\end{array}\end{array}$} & \multirow{3}{*}{$\begin{array}{c}\text { Compound } \\
\mathrm{Cr} \\
\mathrm{Crn} \\
\mathrm{GAA}\end{array}$} & \multicolumn{8}{|c|}{ Genotype } \\
\hline & & \multicolumn{3}{|c|}{ WT } & \multicolumn{2}{|c|}{$\mathrm{HZ}$} & \multicolumn{3}{|c|}{ КО } \\
\hline & & $\begin{array}{c}10.752 \pm 1.15 \\
0.356 \pm 0.04 \\
0.0123 \pm 0.002\end{array}$ & $\begin{array}{c}11.841 \pm 0.44 \\
0.339 \pm 0.50 \\
0.0128 \pm 1.37\end{array}$ & $8.2 \pm 1.2$ & $\begin{array}{l}11.005 \pm 0.439 \\
0.186 \pm 0.049 \\
0.0148 \pm 0.001 \\
\end{array}$ & $\begin{array}{l}10.853 \pm 0.488 \\
0.258 \pm 0.040 \\
0.0134 \pm 0.001\end{array}$ & $\begin{array}{c}0.454 \pm 0.097 \\
0.00945 \pm 0.00004 \\
1.958 \pm 0.070\end{array}$ & $\begin{array}{l}0.489 \pm 0.09^{* * *} \\
<D L-0.02121^{\circ} \\
1.945 \pm 0.064^{* * *}\end{array}$ & $\begin{array}{c}1.4 \pm 0.4 \\
1.3^{\wedge}\end{array}$ \\
\hline \multicolumn{2}{|c|}{ Reference } & {$[39]^{\mathrm{A}}$} & {$[5]^{\mathrm{B}}$} & {$[38]^{\mathrm{C}}$} & {$[39]^{\mathrm{A}}$} & {$[5]^{\mathrm{B}}$} & {$[39]^{\mathrm{A}}$} & {$[5]^{B}$} & {$[38]^{\mathrm{C}}$} \\
\hline
\end{tabular}

In the ${ }^{31} \mathrm{P}$ MR spectra of GAMT KO mouse vs. control mouse brains, a strongly reduced PCR/ATP signal ratio was observed by Renema et al. [38]. In addition, a PGAA/ATP signal ratio was detected, although at a much lower intensity than in muscles (Table 5). Table 5 shows PCR and PGAA concentrations (mM) in GAMT KO mice as estimated with respect to an assumed ATP level of $3 \mathrm{mM}$ [57], as suggested by Renema et al. [38]. To our knowledge, the total ATP content of the GAMT KO mouse brains is unknown. 
Table 5. PCR and PGAA in the brain tissue of GAMT-D WT and KO mice.

\begin{tabular}{cccc}
\hline \multirow{2}{*}{ Tissue } & \multirow{2}{*}{ Compound } & \multicolumn{2}{c}{ Genotype } \\
\cline { 3 - 4 } & & WT & KO \\
\hline Brain & PCR/ATP & $1.36 \pm 0.46$ & $0.31 \pm 0.10$ \\
(phosphate ratios) & PGAA/ATP & N.D. & $0.28 \pm 0.07$ \\
\hline Brain & PCR & $4.08 \pm 1.38$ & $0.93 \pm 0.3$ \\
$(\mathrm{mM})$ & PGAA & N.D. & $0.84 \pm 0.21$ \\
\hline \multicolumn{2}{c}{ [38] } \\
\hline
\end{tabular}

PCR/NTP and PGAA/NTP ratios in Renema et al. are considered as PCR/ATP and PGAA/ATP ratios as suggested [46]. N.D. = not detectable.

A similar trend has been observed by Schmidt et al. [39]. Altogether, these results reveal a striking similarity to the biochemical findings in the brains of human patients $[3,10,24,58-62]$.

Significant adaptive changes in ATP synthase activity have also been observed in the mitochondria of the brains of GAMT KO mice, with an increase of $80 \%$. When normalized to citrate synthase, enzyme activity was still significantly higher in the brain, in contrast to findings in muscle tissue [39]. Moreover, Torremans et al. [5] found significant differences in the concentrations of other guanidine compounds aside from $\mathrm{Cr}$, Crn, and GAA, including higher levels of guanidinosuccinic acid (GSA), argininic acid (ArgA), $\beta$-guanidinopropionic acid ( $\beta$-GPA), $\gamma$-guanidinobutyric acid ( $\gamma$-GBA), and homoarginine (Harg) in GAMT KO mice compared to controls. While some differences were similarly observed in the CSF of human patients ( $\gamma$-GBA and Harg, in addition to the well-known $\mathrm{Cr}$, Crn, and GAA), the increase in brain GSA levels in GAMT KO mice was more pronounced than in human CSF, and the low arginine levels seen in human patients [11] were not observed in mice. These discrepancies found in the brains of GAMT KO mice, as compared with human CSF, could explain the lack of severe neurological symptoms such as epilepsy and ataxia observed in these mice [39]. Indeed, although GAA might be involved in epilepsy in GAMT-D patients $[63,64]$, and although it was present at high levels in the brains of KO mice, epileptic seizures were not observed, suggesting a possible role of other guanidine compounds in helping the brain adapt to the biochemical phenotype due to GAMT-D. In addition, PGAA - a high-energy phosphate able to replace PCR - has long been proposed to explain the mild neurological symptoms observed in GAMT KO mice. Indeed, an increase in PGAA has also been reported in GAMT-D patients [8,65], and a normal amount of this metabolite in the brain is restored by creatine supplementation [65].

In addition, a recent study of partial GAMT-D by RNAi in a 3D model of organotypic reaggregated rat brain cell cultures [66] demonstrated that mild GAA accumulation alone had important consequences on neuron development. Indeed, the authors observed: (1) axonal hypersprouting at early stages that continued up to mature developmental stages; (2) inhibition of natural apoptosis, followed by the induction of non-apoptotic cell death at later stages; and (3) increased expression levels of both $\mathrm{GABA}_{\mathrm{A}}$ receptors and glutamic acid decarboxylase. These features must be taken into account in future studies aimed at deepening knowledge of the pathophysiology of the brains of GAMT KO mice.

More recently [55], studies on brain morphology using high-resolution MRI have been performed in GAMT KO mice. Four brain structures-the hypothalamus, corpus callosum, internal capsule, and fimbria-were found to be abnormal, both in GAMT KO and AGAT KO mice, leading to the conclusion that $\mathrm{Cr}$ depletion was the cause of these anatomical changes.

\subsection{Behavioral Profiling}

To assess the quality of an animal model, authors usually refer to a set of validity criteria. In one of the most cited papers regarding animal model validity, Willner described three criteria that should be fulfilled by a good animal model: (1) construct validity (whether the model and human condition have the same trigger causes); (2) face validity (whether the model shows clinical features typical of the human condition); and (3) predictive validity 
(whether the model responds to treatment in a similar way to humans) [67]. Analysis of the literature shows good construct validity of the GAMT KO model (KO mice are obtained through the inactivation of the murine GAMT gene), whereas face and predictive validity are still uncertain. In fact, although typical biochemical human GAMT-D features have been reported in the serum, urine, brains, skeletal muscle, and hearts of GAMT KO mice, only limited behavioral alterations have been demonstrated, and this is probably due to a limited number of studies addressing GAMT KO behavior phenotyping [5,39,40,68,69]. Studies on the behavior assay of the GAMT-D genetic mouse model are summarized in Figure 1.

\subsubsection{Early Postnatal Behavioral Development}

Although GAMT-D, like phenylketonuria, is a metabolic neurodevelopmental disorder, to the best of our knowledge no data are available on the behavioral phenotype of GAMT-D mice during early postnatal life, since behavioral studies have focused on adult animals [5,39,40,42,68,69]. Schmidt et al. (2004) [39] demonstrated consistent weight differences in female and male GAMT KO mice in comparison with control littermates from the first weeks of life. Moreover, although KO mice are smaller (due to reduced body fat content and muscular hypotonia), no significant difference in length has been reported in pups or adult mice. In addition to body weight and length analysis, studies investigating potential early-onset behavioral deficits in GAMT KO mice are not available. A large set of behavioral assays in both males and females of healthy and mutant mice should be performed in order to identify developmental delay. Communicative behavior, developmental milestone acquisition, neonatal social, maternal, and object recognition, and motor skill development are just some of the typical analyses performed on animal models of neurodevelopmental disorders (such as [70]).

\subsubsection{Neuromuscular Disorder}

Correct $\mathrm{Cr}$ metabolism is important for psychomotor development, and reduced $\mathrm{Cr}$ in GAMT-D causes biochemical alterations in the skeletal muscle. For this reason, several studies have explored movement disorders in GAMT KO mice. Analysis of home cage activity $[5,39]$, results from the open field test $[5,40]$, and voluntary exercise capacity tested by providing running wheels in the home cage [69] did not reveal significant or relevant differences in spontaneous motor activity between healthy and $\mathrm{KO}$ mice, with the exception of the observation that GAMT KO mice entered corners less than heterozygous mice in the open field test, though the authors acknowledge that this observation is difficult to interpret [5]. No effect of genotype was observed in the accelerating rotarod test-an apparatus that tests equilibrium and motor coordination in mice [5,40,42]. Surprisingly, during forced continuous and accelerated running on a treadmill, in which animals learn to run to avoid electric foot shocks, GAMT KO mice showed better performance than healthy mice, running further and gaining more vertical distance [69]. Conversely, analysis of mean grip force using a grip strength meter test revealed impaired neuromotor performance in GAMT KO vs. control mice [5,39,42].

\subsubsection{Learning and Memory Tasks}

As previously reported, intellectual disability is the clinical hallmark of GAMT-D, being present in all affected patients. One of the most relevant studies of cognitive performance in GAMT KO mice was performed by Torremans et al. (2005) [5]. Control, KO, and HZ GAMT-D male mice were subjected to a battery of behavioral tests, starting from the age of six months. In addition to motor analysis in the home cage, WT, $\mathrm{KO}$, and $\mathrm{HZ}$ mice were subjected to the Morris water maze [5,40]—a test widely used to study visual spatial memory and learning in rodents (mice and especially rats). Animals are placed in a circular pool of opaque water where they have to swim to reach a hidden escape platform using external maze cues. After training, animals reach the platform faster. Torremans et al. [5] reported no performance differences between groups during the training phase of the 
Morris water maze test, nor in swimming velocity during the test trial. However, during the test trial GAMT KO mice spent significantly less time in the target quadrant containing the platform compared to healthy and HZ mice (although the frequency of entries to this quadrant did not differ between groups). Torremans et al. also explored other forms of learning and memory using the passive avoidance task-a fear-based test used to evaluate the ability of mice to avoid the preferred dark compartment in which a slight foot shock stimulus was previously delivered. Again, no significant differences were found between groups.

In genetic mouse models of metabolic disease, it is necessary to use cognitive tests that do not require food restriction/reinforcement or lengthy training. For example, the spatial novelty test (designed to estimate the ability of rodents to encode spatial relationships $[71,72]$ ) and the object recognition test (a variant of the delayed non-match-to-sample task that may be solved in the absence of spatial information [73-75]) are recommended because they take advantage of the spontaneous preference that rodents display for novel situations, and are thus appropriate behavioral tests.

In conclusion, due to the limited number of studies on cognitive performance in GAMT-D genetic mouse models, no definitive conclusions can be drawn.

\subsubsection{Social Behavior Tasks}

Several autistic-like features are frequently reported in the GAMT-D human condition, such as the absence of active speech, hyperactivity, aggressive behavior, self-injurious behavior, excessive interest in objects over social interaction, and stereotypic behaviors.

Regarding sociability, to the best of our knowledge only one study [5] reported no significant differences between healthy, $\mathrm{KO}$, and $\mathrm{HZ}$ female mice in the social interaction test. Literature on mouse behavioral tasks relevant to autistic symptoms has grown markedly in the last decades (for a review see [76]).

Social impairments can be detected by the three-chamber social interaction test used to quantify social behavior deficits in transgenic mice exhibiting autistic-like traits. In particular, the test takes advantage of the natural preference of rodents for social interaction and novelty to investigate in two following sessions whether an animal explores an unknown conspecific more than an inanimate object, and whether it shows a preference for interacting with a familiar rodent or an unknown intruder.

With regard to the absence of active speech, communication deficits have not been explored in GAMT KO mice until now. Although mice do not use language, they emit ultrasonic vocalizations to communicate in specific situations (ultrasounds are displayed by pups to elicit maternal care, by juvenile mice during social play, by adult males during courting, etc.) and, thus, quantitative analysis of ultrasonic vocalizations could allow the assessment of deficits in communication skills.

In relation to stereotyped behaviors, mice spontaneously exhibit motor stereotypes-such as circling, jumping, backflips, and self-grooming - that are investigated by observing videotaped or real-time sessions, typically during free exploration of an area. In studies in which animals were exposed to the open field test or in which home cage activity was monitored $[5,39,40]$, results regarding these behavioral patterns are not reported. In the article by Iqbal, a detailed behavioral analysis in the open field apparatus is reported in Supplementary Table S2, but it refers to female GAMT KO mice after 10 weeks of dietary supplementation. Perseveration in the exploration of only one part of a test (e.g., only one object in the object recognition test or only an arm in the delayed alternation test) instead of the normal strategy of exploring the whole environment may be considered analogous to the restricted interest observed in human subjects with autism.

In conclusion, in our opinion behavioral phenotyping of the GAMT-D genetic mouse model is not yet complete. An accurate analysis of behavior during early postnatal development, and better characterization of cognitive function and evaluation of stereotyped behavior, would help to better describe possible deficits in GAMT-D mice, thus increasing the validity of this animal model. 


\section{Discussion}

The discovery of primary disorders of $\mathrm{Cr}$ metabolism and transport has helped clarify the crucial role of creatine in brain metabolism and development. GAMT defects present with early-onset encephalopathy with severe developmental delay/intellectual disability, epilepsy, and movement disorders. From a pathogenetic point of view, this condition results in brain creatine depletion coupled with the accumulation of neurotoxic GAA. Among emerging higher cortical functions, language development is particularly affected by creatine defects. Behavioral disorders in GAMT-deficient subjects have not been well characterized from a clinical point of view, and are usually associated with severe intellectual disability. Like other metabolic neurodevelopmental disorders, such as phenylketonuria, early diagnosis and timely treatment can prevent clinical expression of the disease. Although over $95 \%$ of the whole creatine pool is in the muscle tissue, human disease is essentially characterized by a severe and self-limiting derangement of CNS development and functioning. In contrast, the mouse model of GAMT disorders, which shows a similar pattern of biochemical alterations in the muscle and brain, presents with a prevalent neuromuscular disease with minor or no cognitive impairment. This discrepancy between human and mouse models in terms of neurological impairment is currently unexplained. The murine brain seems less vulnerable to both GAA accumulation (no epilepsy) and $\mathrm{Cr}$ depletion (no severe cognitive impairment), though there is no conclusive evidence that GAA as PGAA may replace the shuttle functions of $\mathrm{Cr}$ in mice differently than in humans. Studies that aimed to explore possible adaptive metabolic variations in GAMT KO mice were inconclusive. While subtle cognitive impairment cannot be ruled out on the basis of present data, the severe intellectual impairment observed in children with GAMT defects is certainly not part of the GAMT KO mouse phenotype.

This is not unusual in mouse models of human diseases. For example, two different mouse models of phenylketonuria, which were developed in strains with different genetic backgrounds (BTBR and C57Bl/6), showed clear differences in behavioral outcome despite comparable biochemical changes in phenylalanine and neurotransmitter concentrations [77]. However, in this case, cognitive impairment severity in the most affected mice (BTBR) also did not replicate that observed in untreated human disease.

The more protracted developmental course of many neurological functions, and the related nervous structure maturation, may be another relevant factor influencing the outcome of early exposure to a neurotoxic noxa in mice and humans.

While awaiting a more systematic assessment of cognitive and behavioral functions, mice with GAMT defects remain an excellent model for the development of new potential treatments targeting the normalization of the metabolic alterations associated with this condition. Indeed, lowering blood GAA coupled with creatine supplementation proved to prevent the derangement of neurological development observed in children with untreated or late-treated GAMT defects [78].

Author Contributions: Conceptualization, T.P., V.L., L.R. and F.N.; writing—original draft preparation, T.P., L.R., F.N. and V.L.; writing-review and editing, F.P., M.M., S.C., C.C. and R.V.; supervision, T.P., L.R. and V.L. All authors have read and agreed to the published version of the manuscript.

Funding: This research received no external funding.

Institutional Review Board Statement: Not applicable.

Informed Consent Statement: Not applicable.

Data Availability Statement: Not applicable.

Conflicts of Interest: The authors declare no conflict of interest. 


\section{References}

1. Hanna-El-Daher, L.; Braissant, O. Creatine synthesis and exchanges between brain cells: What can be learned from human creatine deficiencies and various experimental models? Amino Acids 2016, 48, 1877-1895. [CrossRef]

2. Item, C.B.; Stöckler-Ipsiroglu, S.; Stromberger, C.; Mühl, A.; Alessandrì, M.G.; Bianchi, M.C.; Tosetti, M.; Fornai, F.; Cioni, G. Arginine: Glycine amidinotransferase deficiency: The third inborn error of creatine metabolism in humans. Am. J. Hum. Genet. 2001, 69, 1127-1133. [CrossRef]

3. Stöckler, S.; Holzbach, U.; Hanefeld, F.; Marquardt, I.; Helms, G.; Requart, M.; Hänicke, W.; Frahm, J. Creatine deficiency in the brain: A new, treatable inborn error of metabolism. Pediatr. Res. 1994, 36, 409-413. [CrossRef]

4. Salomons, G.S.; van Dooren, S.J.; Verhoeven, N.M.; Cecil, K.M.; Ball, W.S.; Degrauw, T.J.; Jakobs, C. X-linked creatine-transporter gene (SLC6A8) defect: A new creatine-deficiency syndrome. Am. J. Hum. Genet. 2001, 68, 1497-1500. [CrossRef] [PubMed]

5. Torremans, A.; Marescau, B.; Possemiers, I.; Van Dam, D.; D’Hooge, R.; Isbrandt, D.; De Deyn, P.P. Biochemical and behavioural phenotyping of a mouse model for GAMT deficiency. J. Neurol. Sci. 2005, 231, 49-55. [CrossRef]

6. Stockler-Ipsiroglu, S.; van Karnebeek, C.; Longo, N.; Korenke, G.C.; Mercimek-Mahmutoglu, S.; Marquart, I.; Barshop, B.; Grolik, C.; Schlune, A.; Angle, B.; et al. Guanidinoacetate Methyltransferase (GAMT) Deficiency: Outcomes in 48 Individuals and Recommendations for Diagnosis, Treatment and Monitoring. Mol. Genet. Metab. 2014, 111, 16-25. [CrossRef]

7. Mercimek-Andrews, S.; Salomons, G.S. Creatine Deficiency Syndromes. GeneReviews ${ }^{\circledR}$; Adam, M.P., Ardinger, H.H., Pagon, R.A., Wallace, S.E., Bean, L.J., Mirzaa, G., Amemiya, A., Eds.; University of Washington: Seattle, WA, USA, 2015.

8. Schulze, A. Creatine Deficiency Syndromes. Mol. Cell Biochem. 2003, 244, 143-150. [CrossRef]

9. Stromberger, C.; Bodamer, O.A.; Stöckler-Ipsiroglu, S. Clinical Characteristics and Diagnostic Clues in Inborn Errors of Creatine Metabolism. J. Inherit. Metab. Dis. 2003, 26, 299-308. [CrossRef] [PubMed]

10. Stöckler, S.; Isbrandt, D.; Hanefeld, F.; Schmidt, B.; von Figura, K. Guanidinoacetate Methyltransferase Deficiency: The First Inborn Error of Creatine Metabolism in Man. Am. J. Hum. Genet. 1996, 58, 914-922. [PubMed]

11. Stöckler, S.; Marescau, B.; De Deyn, P.P.; Trijbels, J.M.; Hanefeld, F. Guanidino compounds in guanidinoacetate methyltransferase deficiency, a new inborn error of creatine synthesis. Metabolism 1997, 46, 1189-1193. [CrossRef]

12. Rostami, P.; Hosseinpour, S.; Ashrafi, M.R.; Alizadeh, H.; Garshasbi, M.; Tavasoli, A.R. Primary Creatine Deficiency Syndrome as a Potential Missed Diagnosis in Children with Psychomotor Delay and Seizure: Case Presentation with Two Novel Variants and Literature Review. Acta Neurol. Belg. 2020, 120, 511-516. [CrossRef]

13. Narayan, V.; Mahay, S.; Verma, I.; Puri, R. Case Series of Creatine Deficiency Syndrome Due to Guanidinoacetate Methyltransferase Deficiency. Ann. Indian Acad. Neurol. 2020, 23, 347-351.

14. Yoganathan, S.; Arunachal, G.; Kratz, L.; Varman, M.; Sudhakar, S.; Oommen, S.; Jain, S.; Thomas, M.; Babuji, M. Guanidinoacetate Methyltransferase (GAMT) Deficiency, a Cerebral Creatine Deficiency Syndrome: A Rare Treatable Metabolic Disorder. Ann. Indian Acad. Neurol. 2020, 23, 419-421. [PubMed]

15. Ayanoğlu, M.; Korgali, E.; Sezer, T.; Aydin, H.I.; Sönmez, F.M. Coexistence of Guanidinoacetate Methyltransferase (GAMT) Deficiency and Neuroleptic Malignant Syndrome without Creatine Kinase Elevation. Brain Dev. 2020, 42, 418-420. [CrossRef]

16. Carducci, C.; Birarelli, M.; Leuzzi, V.; Carducci, C.; Battini, R.; Cioni, G.; Antonozzi, I. Guanidinoacetate and creatine plus creatinine assessment in physiological fluids: An effective diagnostic tool for the biochemical diagnosis of arginine: Glycine amidinotransferase and guanidinoacetate methyltransferase deficiencies. Clin. Chem. 2002, 48, 1772-1778. [CrossRef] [PubMed]

17. Khaikin, Y.; Sidky, S.; Abdenur, J.; Anastasi, A.; Ballhausen, D.; Buoni, S.; Chan, A.; Cheillan, D.; Dorison, N.; Goldenberg, A.; et al. Treatment Outcome of Twenty-Two Patients with Guanidinoacetate Methyltransferase Deficiency: An International Retrospective Cohort Study. Eur. J. Paediatr. Neurol. 2018, 22, 369-379. [CrossRef] [PubMed]

18. Almeida, L.S.; Verhoeven, N.M.; Roos, B.; Valongo, C.; Cardoso, M.L.; Vilarinho, L.; Salomons, G.S.; Jakobs, C. Creatine and Guanidinoacetate: Diagnostic Markers for Inborn Errors in Creatine Biosynthesis and Transport. Mol. Genet. Metab. 2004, 82, 214-219. [CrossRef] [PubMed]

19. Mercimek-Mahmutoglu, S.; Ndika, J.; Kanhai, W.; de Villemeur, T.B.; Cheillan, D.; Christensen, E.; Dorison, N.; Hannig, V.; Hendriks, Y.; Hofstede, F.C.; et al. Thirteen New Patients with Guanidinoacetate Methyltransferase Deficiency and Functional Characterization of Nineteen Novel Missense Variants in the GAMT Gene. Hum. Mutat. 2014, 35, 462-469. [CrossRef] [PubMed]

20. Almeida, L.S.; Vilarinho, L.; Darmin, P.S.; Rosenberg, E.H.; Martinez-Muñoz, C.; Jakobs, C.; Salomons, G.S. A Prevalent Pathogenic GAMT Mutation (c.59G>C) in Portugal. Mol. Genet. Metab. 2007, 91, 1-6. [CrossRef] [PubMed]

21. Mercimek-Mahmutoglu, S.; Stoeckler-Ipsiroglu, S.; Adami, A.; Appleton, R.; Araujo, H.C.; Duran, M.; Ensenauer, R.; FernandezAlvarez, E.; Garcia, P.; Grolik, C.; et al. GAMT Deficiency: Features, Treatment, and Outcome in an Inborn Error of Creatine Synthesis. Neurology 2006, 67, 480-484. [CrossRef]

22. Pacheva, I.; Ivanov, I.; Penkov, M.; Kancheva, D.; Jordanova, A.; Ivanova, M. Creatine Deficiency Syndrome Could Be Missed Easily: A Case Report of Guanidinoacetate Methyltransferase Deficiency Presented with Neurodevelopmental Delay, Seizures, and Behavioral Changes, but Normal Structural MRI. Ann. Clin. Lab. Sci. 2016, 46, 557-561. [PubMed]

23. Leuzzi, V.; Mastrangelo, M.; Battini, R.; Cioni, G. Inborn Errors of Creatine Metabolism and Epilepsy: Epilepsy in Creatine Disorders. Epilepsia 2013, 54, 217-227. [CrossRef] [PubMed]

24. Leuzzi, V.; Bianchi, M.C.; Tosetti, M.; Carducci, C.; Cerquiglini, A.; Cioni, G.; Antonozzi, I. Brain Creatine Depletion: Guanidinoacetate Methyltransferase Deficiency (Improving with Creatine Supplementation). Neurology 2000, 55, 1407-1410. [CrossRef] [PubMed] 
25. Stern, W.M.; Winston, J.S.; Murphy, E.; Cross, J.H.; Sander, J.W. Guanidinoacetate Methyltransferase (GAMT) Deficiency: A Rare but Treatable Epilepsy. Pract. Neurol. 2017, 17, 207-211. [CrossRef]

26. Leuzzi, V. Inborn Errors of Creatine Metabolism and Epilepsy: Clinical Features, Diagnosis, and Treatment. J. Child. Neurol. 2002, 17 (Suppl. 3), 3S89-3S97; discussion 3S97. [PubMed]

27. O'Rourke, D.J.; Ryan, S.; Salomons, G.; Jakobs, C.; Monavari, A.; King, M.D. Guanidinoacetate Methyltransferase (GAMT) Deficiency: Late Onset of Movement Disorder and Preserved Expressive Language: Case Report. Dev. Med. Child Neurol. 2009, 51, 404-407. [CrossRef] [PubMed]

28. Hinnell, C.; Samuel, M.; Alkufri, F.; Ashkan, K.; Rahman, Y.; Turner, C.; Dalton, R.N.; Nashef, L. Creatine Deficiency Syndromes: Diagnostic Pearls and Pitfalls. Can. J. Neurol. Sci. 2011, 38, 765-767. [CrossRef]

29. Mercimek-Mahmutoglu, S.; Dunbar, M.; Friesen, A.; Garret, S.; Hartnett, C.; Huh, L.; Sinclair, G.; Stockler, S.; Wellington, S.; Pouwels, P.J.W.; et al. Evaluation of Two Year Treatment Outcome and Limited Impact of Arginine Restriction in a Patient with GAMT Deficiency. Mol. Genet. Metab. 2012, 105, 155-158. [CrossRef]

30. Dhar, S.U.; Scaglia, F.; Li, F.-Y.; Smith, L.; Barshop, B.A.; Eng, C.M.; Haas, R.H.; Hunter, J.V.; Lotze, T.; Maranda, B.; et al. Expanded Clinical and Molecular Spectrum of Guanidinoacetate Methyltransferase (GAMT) Deficiency. Mol. Genet. Metab. 2009, 96, 38-43. [CrossRef]

31. Aydın, H.İ.; Sönmez, F.M. A Novel Mutation in Two Cousins with Guanidinoacetate Methyltransferase (Gamt) Deficiency Presented with Autism. Turk. J. Pediatr. 2019, 61, 92. [CrossRef]

32. Sun, W.; Wang, Y.; Zu, Z.; Jiang, Y.; Lu, W.; Wang, H.; Wu, B.; Zhang, P.; Peng, X.; Zhou, H. First Reported Chinese Case of Guanidinoacetate Methyltransferase Deficiency in a 4-Year-Old Child. Clin. Chim. Acta 2017, 470, 42-45. [CrossRef]

33. Schulze, A.; Ebinger, F.; Rating, D.; Mayatepek, E. Improving Treatment of Guanidinoacetate Methyltransferase Deficiency: Reduction of Guanidinoacetic Acid in Body Fluids by Arginine Restriction and Ornithine Supplementation. Mol. Genet. Metab. 2001, 74, 413-419. [CrossRef] [PubMed]

34. El-Gharbawy, A.H.; Goldstein, J.L.; Millington, D.S.; Vaisnins, A.E.; Schlune, A.; Barshop, B.A.; Schulze, A.; Koeberl, D.D.; Young, S.P. Elevation of Guanidinoacetate in Newborn Dried Blood Spots and Impact of Early Treatment in GAMT Deficiency. Mol. Genet. Metab. 2013, 109, 215-217. [CrossRef]

35. Viau, K.S.; Ernst, S.L.; Pasquali, M.; Botto, L.D.; Hedlund, G.; Longo, N. Evidence-Based Treatment of Guanidinoacetate Methyltransferase (GAMT) Deficiency. Mol. Genet. Metab. 2013, 110, 255-262. [CrossRef] [PubMed]

36. Mercimek-Mahmutoglu, S.; Salomons, G.S.; Chan, A. Case Study for the Evaluation of Current Treatment Recommendations of Guanidinoacetate Methyltransferase Deficiency: Ineffectiveness of Sodium Benzoate. Pediatric Neurol. 2014, 51, 133-137. [CrossRef]

37. Isbrandt, D.; Schmidt, A.; Neu, A.; Roper, J.; Steinfeld, R.; Ullrich, K. Generation of a knockout mouse model for guanidinoacetate methyltransferase (GAMT) deficiency. J. Inherit. Metab. Dis. 2000, 23 (Suppl. 1), 212.

38. Renema, W.K.; Schmidt, A.; van Asten, J.J.; Oerlemans, F.; Ullrich, K.; Wieringa, B.; Isbrandt, D.; Heerschap, A. MR spectroscopy of muscle and brain in guanidinoacetate methyltransferase (GAMT)-deficient mice: Validation of an animal model to study creatine deficiency. Magn. Reson. Med. 2003, 50, 936-943. [CrossRef] [PubMed]

39. Schmidt, A.; Marescau, B.; Boehm, E.A.; Renema, W.K.; Peco, R.; Das, A.; Steinfeld, R.; Chan, S.; Wallis, J.; Davidoff, M.; et al. Severely altered guanidino compound levels, disturbed body weight homeostasis and impaired fertility in a mouse model of guanidinoacetate N-methyltransferase (GAMT) deficiency. Hum. Mol. Genet. 2004, 13, 905-921. [CrossRef] [PubMed]

40. Iqbal, F.; Hoeger, H.; Lubec, G.; Bodamer, O. Biochemical and behavioral phenotype of $A G A T$ and GAMT deficient mice following long-term Creatine monohydrate supplementation. Metab. Brain Dis. 2017, 32, 1951-1961. [CrossRef] [PubMed]

41. Stechman, M.J.; Ahmad, B.N.; Loh, N.Y.; Reed, A.A.; Stewart, M.; Wells, S.; Hough, T.; Bentley, L.; Cox, R.D.; Brown, S.D.; et al. Establishing normal plasma and 24-h urinary biochemistry ranges in $\mathrm{C} 3 \mathrm{H}, \mathrm{BALB} / \mathrm{c}$ and C57BL/6J mice following acclimatization in metabolic cages. Lab. Anim. 2010, 44, 218-225. [CrossRef]

42. Sasani, A.; Hornig, S.; Grzybowski, R.; Cordts, K.; Hanff, E.; Tsikas, D.; Boger, R.; Gerloff, C.; Isbrandt, D.; Neu, A.; et al. Muscle phenotype of AGAT- and GAMT-deficient mice after simvastatin exposure. Amino Acids 2020, 52, 73-85. [CrossRef] [PubMed]

43. Kan, H.E.; Renema, W.K.; Isbrandt, D.; Heerschap, A. Phosphorylated guanidinoacetate partly compensates for the lack of phosphocreatine in skeletal muscle of mice lacking guanidinoacetate methyltransferase. J. Physiol. 2004, 560 Pt 1, $219-229$. [CrossRef]

44. Kan, H.E.; Meeuwissen, E.; van Asten, J.J.; Veltien, A.; Isbrandt, D.; Heerschap, A. Creatine uptake in brain and skeletal muscle of mice lacking guanidinoacetate methyltransferase assessed by magnetic resonance spectroscopy. J. Appl. Physiol. 2007, 102, 2121-2127. [CrossRef]

45. Hakim, C.H.; Li, D.; Duan, D. Monitoring murine skeletal muscle function for muscle gene therapy. Methods Mol. Biol. 2011, 709, 75-89. [PubMed]

46. Heerschap, A.; Kan, H.E.; Nabuurs, C.I.H.C.; Renema, W.K.; Isbrandt, D.; Wieringa, B. In vivo magnetic resonance spectroscopy of transgenic mice with altered expression of guanidinoacetate methyltransferase and creatine kinase isoenzymes. In Creatine and Creatine Kinase in Health and Disease; Salomons, G.S., Wyss, M., Eds.; Springer: Berlin/Heidelberg, Germany, 2007; Chapter 7; pp. 119-148.

47. Wyss, M.; Kaddurah-Daouk, R. Creatine and creatinine metabolism. Physiol. Rev. 2000, 80, 1107-1213. [CrossRef] [PubMed] 
48. Van Pilsum, J.F.; Olsen, B.; Taylor, D.; Rozycki, T.; Pierce, J.C. Transamidinase activities, in vitro, of tissues from various mammals and from rats fed in protein-free, creatine-supplemented and normal diets. Arch. Biochem. Biophys. 1963, 100, 520-524. [CrossRef]

49. Boehm, E.A.; Radda, G.K.; Tomlin, H.; Clark, J.F. The utilisation of creatine and its analogues by cytosolic and mitochondrial creatine kinase. Biochim. Biophys. Acta 1996, 1274, 119-128. [CrossRef]

50. Balestrino, M.; Adriano, E. Presence of guanidinoacetate may compensate creatine absence and account for less statin-induced muscle damage in GAMT-deficient compared to AGAT-deficient mice. Amino Acids 2020, 52, 667-669. [CrossRef] [PubMed]

51. Ilas, J.; Mühl, A.; Stöckler-Ipsiroglu, S. Guanidinoacetate methyltransferase (GAMT) deficiency: Non-invasive enzymatic diagnosis of a newly recognized inborn error of metabolism. Clin. Chim. Acta 2000, 290, 179-188. [CrossRef]

52. Barsunova, K.; Vendelin, M.; Birkedal, R. Marker enzyme activities in hindleg from creatine-deficient AGAT and GAMT KO mice-differences between models, muscles, and sexes. Sci. Rep. 2020, 10, 7956-7963. [CrossRef] [PubMed]

53. Schulze, A.; Bachert, P.; Schlemmer, H.; Harting, I.; Polster, T.; Salomons, G.S.; Verhoeven, N.M.; Jakobs, C.; Fowler, B.; Hoffmann, G.F.; et al. Lack of creatine in muscle and brain in an adult with GAMT deficiency. Ann. Neurol. 2003, 53, $248-251$. [CrossRef]

54. Perasso, L.; Cupello, A.; Lunardi, G.L.; Principato, C.; Gandolfo, C.; Balestrino, M. Kinetics of creatine in blood and brain after intraperitoneal injection in the rat. Brain Res. 2003, 974, 37-42. [CrossRef]

55. Sinha, A.; Ahmed, S.; George, C.; Tsagaris, M.; Naufer, A.; von Both, I.; Tkachyova, I.; van Eede, M.; Henkelman, M.; Schulze, A. Magnetic resonance imaging reveals specific anatomical changes in the brain of Agat- and Gamt-mice attributed to creatine depletion and guanidinoacetate alteration. J. Inherit. Metab. Dis. 2020, 43, 827-842. [CrossRef]

56. Torack, R.M.; Alcala, H.; Gado, M.; Burton, R. Correlative Assay of Computerized Cranial Tomography (CCT), Water Content and Specific Gravity in Normal and Pathological Postmortem Brain. J. Neuropathol. Exp. Neurol. 1976, 35, 385-392. [CrossRef] [PubMed]

57. Gorell, J.M.; Dolkart, P.H.; Ferrendelli, J.A. Regional levels of glucose, amino acids, high energy phosphates, and cyclic nucleotides in the central nervous system during hypoglycemic stupor and behavioral recovery. J. Neurochem. 1976, 27, 1043-1049. [CrossRef]

58. Schulze, A.; Hess, T.; Wevers, R.; Mayatepek, E.; Bachert, P.; Marescau, B.; Knopp, M.V.; De Deyn, P.P.; Bremer, H.J.; Rating, D. Creatine deficiency syndrome caused by guanidinoacetate methyltransferase deficiency: Diagnostic tools for a new inborn error of metabolism. J. Pediatr. 1997, 131, 626-631. [CrossRef]

59. Van der Knaap, M.S.; Verhoeven, N.M.; Maaswinkel-Mooij, P.; Pouwels, P.J.; Onkenhout, W.; Peeters, E.A.; Stockler-Ipsiroglu, S.; Jakobs, C. Mental retardation and behavioral problems as presenting signs of a creatine synthesis defect. Ann. Neurol. 2000, 47, 540-543. [CrossRef]

60. Ganesan, V.; Johnson, A.; Connelly, A.; Eckhardt, S.; Surtees, R.A. Guanidinoacetate methyltransferase deficiency: New clinical features. Pediatr. Neurol. 1997, 17, 155-157. [CrossRef]

61. Thiel, T.; Ensenauer, R.; Hennig, J.; Lehnert, W. In vivo magnetic resonance spectroscopy in a patient with creatine deficiency syndrome: New aspects on mechanism of creatine uptake in brain and muscle. In Proceedings of the 9th Annual Meeting ISMRM, Glasgow, Scotland, 21-27 April 2001; p. 582.

62. Frahm, J.; Hanefeld, F. Localized proton magnetic resonance spectroscopy of brain disorders in childhood. In Magnetic Resonance Spectroscopy and Imaging in Neurochemistry, Vol. 8. Advances in Neurochemistry; Bachelard, H., Ed.; Plenum Press: New York, NY, USA, 1997; pp. 329-403.

63. Neu, A.; Neuhoff, H.; Trube, G.; Fehr, S.; Ullrich, K.; Roeper, J.; Isbrandt, D. Activation of GABA(A) receptors by guanidinoacetate: A novel pathophysiological mechanism. Neurobiol. Dis. 2002, 11, 298-307. [CrossRef] [PubMed]

64. Marques, E.P.; Wyse, A.T.S. Guanidinoacetate Methyltransferase Deficiency: A Review of Guanidinoacetate Neurotoxicity. J. Inborn Errors Metab. Screen. 2016, 4, 1-6. [CrossRef]

65. Bianchi, M.C.; Tosetti, M.; Battini, R.; Leuzzi, V.; Alessandri', M.G.; Carducci, C.; Antonozzi, I.; Cioni, G. Treatment monitoring of brain creatine deficiency syndromes: A 1H- and 31P-MR spectroscopy study. AJNR Am. J. Neuroradiol. 2007, 28, 548-554.

66. Hanna-El-Daher, L.; Béard, E.; Henry, H.; Tenenbaum, L.; Braissant, O. Mild guanidinoacetate increase under partial guanidinoacetate methyltransferase deficiency strongly affects brain cell development. Neurobiol. Dis. 2015, 79, 14-27. [CrossRef]

67. Willner, P. The validity of animal models of depression. Psychopharmacology 1984, 83, 1-16. [CrossRef]

68. Kan, H.E.; Buse-Pot, T.E.; Peco, R.; Isbrandt, D.; Heerschap, A.; de Haan, A. Lower force and impaired performance during high-intensity electrical stimulation in skeletal muscle of GAMT-deficient knockout mice. Am. J. Physiol. Cell Physiol. 2005, 289, C113-C119. [CrossRef] [PubMed]

69. Lygate, C.A.; Aksentijevic, D.; Dawson, D.; ten Hove, M.; Phillips, D.; de Bono, J.P.; Medway, D.J.; Sebag-Montefiore, L.; Hunyor, I.; Channon, K.M.; et al. Living without creatine: Unchanged exercise capacity and response to chronic myocardial infarction in creatine-deficient mice. Circ. Res. 2013, 112, 945-955. [CrossRef] [PubMed]

70. Fiori, E.; Oddi, D.; Ventura, R.; Colamartino, M.; Valzania, A.; D'Amato, F.R.; Bruinenberg, V.; van der Zee, E.; Puglisi-Allegra, S.; Pascucci, T. Early-onset behavioral and neurochemical deficits in the genetic mouse model of phenylketonuria. PLoS ONE 2017, 12, e0183430. [CrossRef] [PubMed]

71. Poucet, B. Object exploration, habituation, and response to spatial change in rats following septal or medial frontal cortical damage. Behav. Neurosci. 1989, 103, 1009-1016. [CrossRef] [PubMed]

72. Roullet, P.; Mele, A.; Ammassari-Teule, M. Ibotenic acid lesions of the nucleus accumbens improve detection of spa- tial novelty in poor spatial learner mice. Behav. Neurosci. 1997, 111, 976-984. [CrossRef] 
73. Clark, R.E.; Zola, M.S.; Squire, L.R. Impaired recognition memory in rats after damage to the hippocampus. J. Neurosci. 2000, 20, 8853-8860. [CrossRef]

74. Dix, S.L.; Aggleton, J.P. Extending the spontaneous preference test of recognition: Evidence of object-location and object-context recognition. Behav. Brain Res. 1999, 99, 191-200. [CrossRef]

75. Mumby, D.G. Perspectives on object-recognition memory following hippocampal damage: Lessons from studies in rats. Behav. Brain Res. 2001, 127, 159-181. [CrossRef]

76. Silverman, J.L.; Yang, M.; Lord, C.; Crawley, J.N. Behavioural phenotyping assays for mouse models of autism. Nat. Rev. Neurosci. 2010, 11, 490-502. [CrossRef] [PubMed]

77. Bruinenberg, V.M.; van der Goot, E.; van Vliet, D.; de Groot, M.J.; Mazzola, P.N.; Heiner-Fokkema, M.R.; van Faassen, M.; van Spronsen, F.J.; van der Zee, E.A. The Behavioral Consequence of Phenylketonuria in Mice Depends on the Genetic Background. Front. Behav Neurosci. 2016, 10, 233. [CrossRef] [PubMed]

78. Schulze, A.; Hoffmann, G.F.; Bachert, P.; Kirsch, S.; Salomons, G.S.; Verhoeven, N.M.; Mayatepek, E. Presymptomatic treatment of neonatal guanidinoacetate methyltransferase deficiency. Neurology 2006, 67, 719-721. [CrossRef] 